\title{
Tooth loss in individuals under periodontal maintenance therapy: prospective study
}

\section{Telma Campos Medeiros Lorentz ${ }^{(a)}$ Luís Otávio Miranda Cota ${ }^{(a)}$ José Roberto Cortelli(b) Andréia Maria Duarte Vargas ${ }^{(c)}$ Fernando Oliveira Costa ${ }^{(a)}$}

(a) PhD, Division of Periodontics, School of Dentistry, Federal University of Minas Gerais, Belo Horizonte, Brazil.

(b) PhD, Department of Dentistry, Periodontics Research Division, University of Taubaté, São Paulo, Brazil.

(c) PhD, Division of Preventive Dentistry, School of Dentistry, Federal University of Minas Gerais, Belo Horizonte, Brazil.

\section{Corresponding author:}

Fernando de Oliveira Costa

Faculdade de Odontologia, UFMG

Departamento CPD

Av. Antonio Carlos, 6627 - Pampulha

Belo Horizonte - MG - Brazil

CEP: $31270-901$

E-mail:focperio@uol.com.br

Received for publication on Oct 06, 2009 Accepted for publication on Mar 09, 2010

\begin{abstract}
This prospective study aimed to evaluate the incidence, the underlying reasons, and the influence of predictors of risk for the occurrence of tooth loss (TL) in a program of Periodontal Maintenance Therapy (PMT). The sample was composed of 150 complier individuals diagnosed with chronic moderate-severe periodontitis who had finished active periodontal treatment and were incorporated in a program of PMT. Social, demographic, behavioral and biological variables were collected at quarterly recalls, over a 12-month period. The effect of predictors of risk of and confounding for the dependent variable TL was tested by univariate and multivariate analysis, as well as the underlying reasons and the types of teeth lost. During the monitoring period, there was a considerable improvement in periodontal clinical parameters, with a stability of periodontal status in the majority of individuals. Twenty-eight subjects $(18.66 \%)$ had TL, totaling 47 lost teeth $(1.4 \%)$. The underlying reasons for TL were: periodontal disease $(\mathrm{n}=34,72.3 \%)$, caries $(\mathrm{n}=3$, $6.4 \%)$, prosthetic reasons $(\mathrm{n}=9,19.2 \%)$, and endodontic reasons $(\mathrm{n}=1$, $2.1 \%)$. Additionally, subjects with $10 \%$ of sites with probing depth between 4 and $6 \mathrm{~mm}$ were 5 times more likely to present TL $(\mathrm{OR}=5.13$, 95\% CI 2.04-12.09). In this study, the incidence of TL was small and limited to few individuals. Additionally, gender and severity of periodontitis were significantly associated with TL during the monitoring period.
\end{abstract}

Descriptors: Epidemiology; Periodontitis; Risk factors; Tooth loss.

\section{Introduction}

Tooth loss (TL) is one of the most visible results of the development of periodontal disease, and causes physiological and psychological impacts on patient's life. Longitudinal studies have demonstrated the effectiveness of periodontal therapy in arresting the progression of periodontal disease, maintaining gingival health and preventing TL. ${ }^{1,2}$

The dental mortality has already been reported in longitudinal studies through the combination of lost teeth during active therapy and Periodontal Maintenance Therapy (PMT). ${ }^{3-6}$ The vast majority of studies reported TL only during the maintenance period. ${ }^{3,5,7-11}$ However, recent studies recommended the description of TL prevalence during the active therapy and its incidence during PMT as a mean of assessing the overall effectiveness of periodontal therapies. ${ }^{12,13}$ Moreover, most of the studies on TL in programs of PMT have retrospective designs, , $3,6-8,14_{\text {and }}$ 
a consequence, data may reflect the traditional bias related to the design methodology.

The periodontitis has been singled out as one of the main causes of dental mortality after 45 years of age, ${ }^{15}$ and has been associated to serious negative impacts on quality of life of periodontally susceptible individuals. Thus, periodontal maintenance programs must make efforts to stabilize periodontal tissues and minimize, as a priority goal, the occurrence of additional TL over time.

In addition, the identification of variables of risk for TL in programs of PMT can help clinicians and periodontists to establish the frequency of visits, and to improve the adherence to maintenance programs with greater compliance of individuals. Accordingly, the objective of this prospective cohort study was to describe the incidence of TL in a program of PMT and investigate the underlying reasons and risk variables associated with TL.

The hypothesis under testing is that programs of PTM can promote periodontal stability, and therefore minimize the incidence of TL.

\section{Methods}

This study was approved by the Research Ethics Committee of the Federal University of Minas Gerais - Brazil, under the paragraph opinion ETIC 060/2005.

\section{Cohort study}

The sample for this prospective cohort study was composed of 150 compliers individuals who were included in a program of PMT, and monitored during 12 months in consecutive 4 quarterly recalls, named PMT1 (baseline), PMT2, PMT3 and PMT4. These individuals presented the following criteria: diagnosis of chronic moderate-advanced periodontitis before the active periodontal treatment, and completion of active periodontal therapy in a period of less than 4 months before the entry in the maintenance program. All steps of the methodology adopted in the present study, as well as sample characteristics, periodontal clinical examination, determination of clinical periodontal status, periodontal monitoring, and intra-examiner reliability on each quarterly recall were previously described by Lorentz et al.
(2009). ${ }^{2}$

As described elsewhere, one feature of the present study that is of particular interest is the exclusion of third molars from periodontal examination, except when they occupied the position of second molars and were in complete eruption and in function.

\section{Reasons underlying tooth loss}

The reasons underlying TL were categorized into: (1) periodontal [teeth with severe clinical attachment loss (CAL) and deep probing depth (PD), furcation involvement, severe mobility, and advanced bone loss that not responded satisfactorily to active therapy or any of the procedures during PMT)], (2) cariogenic (crown or root advanced destruction); (3) prosthetic (teeth incompatible with appropriate restorative procedures) (4) endodontic (non treatable endodontic pathological processes); and (5) root fracture (longitudinal and/or horizontal fractures leading to a non satisfactory crown-root ratio obtained through surgical procedures). During the PMT, the decision of tooth extraction was based on clinical and radiographic individual dental conditions.

\section{Statistical analysis}

Statistical analysis included a characterization of the sample and descriptive analysis of variables of interest, a univariate analysis, and a multivariate logistic regression. Independent variables of interest (demographic, behavioral, biological, and social) were tested to determine which of them could be associated to the additional TL over the 12-month interval of PMT. The parametric and non-parametric tests (Chi-squared, Friedman, Kruskal-Wallis, Fisher's exact, $t$-Student, and Mann-Whitney) were used, where appropriate.

A logistic regression analysis was performed to investigate the association between the dependent variable TL (occurrence of at least 1 tooth loss from PMT1 to PMT4) and the following independent predictors of risk: gender, age, marital status, diabetes, smoking (smokers/former smokers, those reporting to have smoked more than 100 cigarettes throughout their lives, and non-smokers), alcohol use (yes/ 
no), family income [(less/equal, and greater than 2 Brazilian minimum salaries), bleeding on probing (BOP) in more than $30 \%$ of sites, $\mathrm{PD} \geq 4 \mathrm{~mm}$ in more than $30 \%$ of sites, PD between 4 and $6 \mathrm{~mm}$ up to $10 \%$ of sites, and CAL $\geq 3 \mathrm{~mm}$ in more than $30 \%$ of sites.

Confounding variables were determined if their removal from the model caused changes greater than $15 \%$ in the $\beta$ coefficient. All variables included in the final multivariate model were determined to be independent through the assessment of their collinearity. Odds ratio (OR) estimates and their confidence intervals $(\mathrm{CI})$ were calculated and reported.

All tests were performed using statistical software (SPSS Inc., version 14.0, Chicago, IL, USA). Results were considered significant if a $p$-value lower than $5 \%$ was attained $(\mathrm{p}<0.05)$.

\section{Results}

In the present study, individuals presented a mean age of $44.9 \pm 9.5$ years (range 18-74 years). Sixteen subjects $(10.7 \%)$ were diabetic, and 61 subjects $(40.7 \%)$ were smokers/former smokers. It is important to highlight that most of the sample had a low socioeconomic status. Periodontal status of the sample was also described by Lorentz et al. (2009). ${ }^{2}$ During the interval from PMT1 to PMT4, an increase in the number of sites with PD and $\mathrm{CAL} \leq 3 \mathrm{~mm}$, and a consequent reduction in the number of sites with PD of $\geq 4 \mathrm{~mm}$, could be observed. In this manner, sample from the present study demonstrated a considerable improvement in clinical periodontal parameters, with a stability of periodontal status in the majority of individuals.

In PMT1, PMT2, PMT3, and PMT4, individu- als presented 3,393, 3,376, 3,362, and 3,346 teeth, respectively. In PMT1, there were reported 807 lost teeth. Hence, it is observed that TL in PMT2, PMT3 and PMT4 was respectively, 17, 14, and 16 teeth. Thus, in PMT4 it was registered a total of 854 lost teeth (mean of 5.69, 95\% CI 5.04-6.34).

The incidence rate of TL, when considering individuals and teeth as the sample units (from PMT1 to PMT4), was respectively $18.66 \%$ ( $\mathrm{n}=28$ subjects who had lost at least 1 tooth) and $1.38 \%(\mathrm{n}=47$ teeth lost), with an average of 0.31 lost teeth per subject.

Table 1 shows the frequency of TL in relation to age in the sample unit individuals. It is observed that most of the subjects with TL $(67.9 \%)$ were over 40 years of age.

The Table 2 shows the average of present teeth by age groups from PMT1 to PMT4. There is a significant decrease in the number of present teeth in the higher age groups in relation to the lower age groups $(\mathrm{p}=0.001)$.

Table 1 - Frequency of tooth loss in relation to age considering individuals as the sample unit $(n=150$; from PMT1 to PMT4).

\begin{tabular}{c|r|r|r|r|r}
\hline \multirow{2}{*}{ Age group } & \multicolumn{5}{|c}{ Tooth loss } \\
\cline { 2 - 5 } & \multicolumn{2}{|c|}{ Yes } & \multicolumn{2}{c}{ No } & \multirow{2}{*}{ Total } \\
\cline { 2 - 5 } & $n$ & $\%$ & $n$ & $\%$ & \\
\hline Up to 30 years & 2 & 7.1 & 14 & 11.5 & 16 \\
\hline 31 to 40 years & 7 & 25.0 & 26 & 21.3 & 33 \\
\hline 41 to 49 years & 11 & 39.3 & 43 & 35.2 & 54 \\
\hline 50 or more & 8 & 28.6 & 39 & 32.0 & 47 \\
\hline Total & 28 & 100.0 & 122 & 100.0 & 150 \\
\hline
\end{tabular}

Chi-square test ( $p<0.001$ for all comparisons).
Table 2 - Average of present teeth in relation to age groups from PMT1 to PMT4.

\begin{tabular}{c|c|c|c|c|c}
\hline \multirow{2}{*}{ Age group } & \multirow{2}{*}{$\begin{array}{c}\text { Number of } \\
\text { individuals }\end{array}$} & $\begin{array}{c}\text { PMT1 } \\
(n=3,393)\end{array}$ & $\begin{array}{c}\text { PMT2 } \\
(n=3,376)\end{array}$ & $\begin{array}{c}\text { PMT3 } \\
(n=3,362)\end{array}$ & $\begin{array}{c}\text { PMT4 } \\
(n=3,346)\end{array}$ \\
\hline 330 years & 16 & $25.5 \pm 3.2$ & $25.4 \pm 3.2$ & $25.4 \pm 3.2$ & $25.4 \pm 3.3$ \\
\hline $31-40$ years & 33 & $23.5 \pm 3.3$ & $23.4 \pm 3.4$ & $23.3 \pm 3.3$ & $23.2 \pm 3.4$ \\
\hline $41-49$ years & 54 & $22.2 \pm 4.1$ & $22.1 \pm 4.2$ & $22.1 \pm 4.2$ & $21.9 \pm 4.4$ \\
\hline$\geq 50$ years & 47 & $21.4 \pm 3.8$ & $21.3 \pm 3.8$ & $21.2 \pm 3.9$ & $21.1 \pm 3.9$ \\
\hline
\end{tabular}

*Kruskal-Wallis test for comparisons between age groups $(p<0.001)$; Friedman test for comparisons between intervals of PMT (periodontal maintenance therapy) $(p<0.001)$. 
Table 3 reports the distribution of individuals according to the number of lost teeth during PMT with respect to gender. Among the 28 individuals who presented TL from PMT1 to PMT4, 15 individuals were male and 13 female. It is important to notice that men had significantly greater TL than women $(\mathrm{p}=0.015)$, whereas this difference was not significant when considering the two cut off points proposed: 1 to 3 teeth lost or $\geq 4$ teeth lost $(\mathrm{p}=1.00)$.

The reasons underlying TL with respect to gender and the type of lost teeth, when considering teeth as the sample unit $(n=47)$, are reported in Table 4. It was observed that of the 47 lost teeth, 30 occurred in men and 17 in women. When analyzing reasons underlying TL in a dicothomous manner, that is, TL for periodontal disease and the other reasons altogether, it was revealed that the number of teeth lost for periodontal reasons $(\mathrm{n}=34,72.3 \%)$ was significantly greater than TL for other reasons $(n=13$, $27.7 \%)(p=0.011)$. In addition, Table 4 shows reasons underlying tooth loss in relation to gender and type of lost teeth ( $n=47)$.

Table 5 shows a logistic regression model including the predictors of risk for TL. The final adjusted model revealed that the odds of men to present TL was 3 times higher than women $(\mathrm{OR}=3.16,95 \%$ CI 1.28-7.78), and that the odds of subjects with $10 \%$ of sites with PD between 4 and $6 \mathrm{~mm}$ to present $\mathrm{TL}$ was 5 times higher $(\mathrm{OR}=5.13,95 \% \mathrm{CI}$ : 2.04-12.9).

\section{Discussion}

Conflicting data of annual TL in longitudinal studies have been reported. ${ }^{4,6,8,13-17}$ In a similar way to other prospective studies of TL in periodontal susceptible individuals, the present study aimed to describe the TL for periodontal disease and to analyze possible predictors of risk to the occurrence of this event.

The most common cause of TL in the present study was periodontal disease $(72.3 \%)$, which coincides with studies. . $^{5,713,16-18}$

The present study reports similarities with previous studies ${ }^{6,9,17}$ in relation to the type of lost teeth during PMT. Teeth from the upper arch were lost more often that those from the lower arch. The frequency of TL was observed in a decreasing frequency as following: upper molars, first upper pre-

Table 3 - Distribution of individuals according to the number of teeth lost during PMT in relation to gender $(\mathrm{n}=150$ individuals).

\begin{tabular}{c|c|c|c|c}
\hline $\begin{array}{c}\text { Individuals } \\
(\mathrm{n}=150)\end{array}$ & $\begin{array}{c}1 \text { to } 3 \text { lost } \\
\text { teeth* }\end{array}$ & $\begin{array}{c}\geq 4 \text { lost } \\
\text { teeth* }\end{array}$ & $\begin{array}{c}\text { Total of individuals } \\
\text { with tooth loss** }\end{array}$ & $\begin{array}{c}\text { Total of individuals } \\
\text { without tooth loss** }\end{array}$ \\
\hline Male $(\mathrm{n}=51)$ & $13(86.7 \%)$ & $2(13.3 \%)$ & $15(29.4 \%)$ & $36(70.6 \%)$ \\
\hline Female $(\mathrm{n}=99)$ & $12(92.3 \%)$ & $1(7.7 \%)$ & $13(13.1 \%)$ & $86(86.9 \%)$ \\
\hline
\end{tabular}

*Exact's Fisher test $(p=1.00),{ }^{* *}$ Chi-Squared test $(p=0.015)$.

Table 4 - Reasons underlying tooth loss in relation to gender and type of lost teeth ( $n=47$ teeth).

\begin{tabular}{|c|c|c|c|c|c|c|c|c|}
\hline & & \multicolumn{4}{|c|}{ Tooth loss } & \multirow{2}{*}{\multicolumn{2}{|c|}{ Total of lost teeth }} & \multirow{3}{*}{$p$} \\
\hline & & \multicolumn{2}{|c|}{ Periodontal reasons } & \multicolumn{2}{|c|}{ Other reasons } & & & \\
\hline & & $\mathrm{n}$ & $\%$ & $n$ & $\%$ & $\mathrm{n}$ & $\%$ & \\
\hline \multirow{3}{*}{$\begin{array}{l}\bar{d} \\
\overline{0} \\
\bar{\Phi} \\
0\end{array}$} & Male & 25 & 73.5 & 5 & 38.5 & 30 & 63.8 & \multirow{3}{*}{$0.011^{*}$} \\
\hline & Female & 9 & 26.5 & 8 & 61.5 & 17 & 36.2 & \\
\hline & Total & 34 & 72.3 & 13 & 27.7 & 47 & 100 & \\
\hline \multirow{5}{*}{ 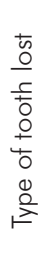 } & Molars & 12 & 35.3 & 4 & 30.8 & 16 & 34.0 & \multirow{5}{*}{$0.073^{* *}$} \\
\hline & Premolars & 10 & 29.4 & 4 & 30.8 & 14 & 29.8 & \\
\hline & Canines & 0 & 0.0 & 3 & 23.0 & 3 & 6.4 & \\
\hline & Incisors & 12 & 35.3 & 2 & 15.4 & 14 & 29.8 & \\
\hline & Total & 34 & 100 & 13 & 100 & 47 & 100 & \\
\hline
\end{tabular}


Table 5 - Initial and final multivariate model of logistic regression for tooth loss.

\begin{tabular}{|c|c|c|c|c|c|c|c|}
\hline & Variable & Coef & Wald & $\mathrm{p}$ & OR & & \\
\hline & Gender (male) & -1.078 & 4.631 & 0.031 & 0.340 & 0.128 & 0.908 \\
\hline & Age & - & 0.985 & 0.805 & - & - & - \\
\hline & Up to 30 years & 0.219 & 0.048 & 0.827 & 1.245 & 0.174 & 8.891 \\
\hline & 31 to 40 years & 0.656 & 0.905 & 0.341 & 1.927 & 0.499 & 7.440 \\
\hline & 41 to 49 years & 0.401 & 0.437 & 0.509 & 1.494 & 0.455 & 4.908 \\
\hline & Marital status & 0.295 & 0.293 & 0.588 & 1.343 & 0.461 & 3.914 \\
\hline & Diabetes & 1.073 & 2.333 & 0.127 & 2.924 & 0.738 & 11.591 \\
\hline 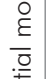 & $\begin{array}{l}\text { Smoking (smoker/former smoker } \\
\text { and no smoker) }\end{array}$ & -0.366 & 0.427 & 0.514 & 0.694 & 0.232 & 2.078 \\
\hline & Alcohol use & 0.856 & 2.584 & 0.108 & 2.353 & 0.829 & 6.679 \\
\hline & Family income $\leq 2 \mathrm{BMS}$ & 0.330 & 0.384 & 0.536 & 1.391 & 0.490 & 3.954 \\
\hline & BOP in more than $30 \%$ of sites & -0.283 & 0.124 & 0.724 & 0.753 & 0.156 & 3.633 \\
\hline & $P D \geq 4 \mathrm{~mm}$ in more than $30 \%$ of sites & 0.958 & 1.442 & 0.230 & 2.606 & 0.546 & 12.441 \\
\hline & PD between $4-6 \mathrm{~mm}$ until $10 \%$ of sites & 1.578 & 7.807 & 0.005 & 4.847 & 1.602 & 14.666 \\
\hline & CAL $\geq 3 \mathrm{~mm}$ in more than $30 \%$ of sites & 18.562 & 0.000 & 0.999 & - & - & - \\
\hline & Constant & 21.221 & 0.000 & 0.999 & - & - & - \\
\hline$\frac{\overline{0}}{0}$ & Male gender & 1.1503 & 6.3192 & 0.0119 & 3.16 & 1.28 & 7.78 \\
\hline$\frac{\hat{\varepsilon}}{\bar{\sigma}}$ & PD between $4-6 \mathrm{~mm}$ up to $10 \%$ of sites & 1.6360 & 12.3283 & 0.0004 & 5.13 & 2.04 & 12.90 \\
\hline$\stackrel{\oplus}{\longleftarrow}$ & Constant & 1.6050 & 15.4829 & 0.0001 & - & - & - \\
\hline
\end{tabular}

$\mathrm{OR}=$ odds ratio, $\mathrm{Cl}=$ confidence interval, $\mathrm{BMS}=$ Brazilian minimum salary equivalent to 190 dolars, $\mathrm{BOP}=$ bleeding on probing, $\mathrm{PD}=$ probing depth, $\mathrm{CAL}=$ clinical attachment loss.

molars, lower second molars, lower incisors, and canines.

The logistic regression analysis estimated the influence of predictors of risk for TL during the maintenance therapy. The final adjusted model revealed that the odds of men to present TL was three times higher than women $(\mathrm{OR}=3.16,95 \%$ CI $1.28-7.78)$. This data is similar to that reported by Fardal et al. (2004). ${ }^{8}$ Individuals with $10 \%$ of sites with PD between 4 and $6 \mathrm{~mm}$ presented 5 times more chances for $\mathrm{TL}(\mathrm{OR}=5.13,95 \%$ CI 2.04-12.9). Various studies have pointed out that men were at higher risk for TL than women. This fact is probably related to a lower frequency of the male gender to search for dental treatment and to adhere to PMT programs.

It is widely accepted that smoking and diabetes are risk factors related to the progression of periodontitis and TL. $.15,19,20$ Effects of smoking were also reported to be dose-dependent ${ }^{4}$ and a good predictor of alveolar bone loss. ${ }^{21}$ It is interesting to observe that smoking and diabetes were not associated with TL in the present study. We hypothesized that this lack of association could be related to three factors: (a) a relatively short follow-up time, (b) effectiveness and efficiency of the program of PMT in neutralize powerful determinants of risk, (c) sample of compliers able to minimize the deleterious primary effect of dental biofilm. It is also important to highlight that despite the high rates of individuals presenting BOP and poor plaque index, the periodontal status of individuals substantially improved from PMT1 to PMT4.

The TL in our study was more frequent in individuals over 40 years of age. This fact is corroborated by numerous studies. ${ }^{1,6,8,13,17,19}$ However, higher age groups were not associated with TL in the final multivariate model. This fact can be substantiated by the hypothesis previously cited or by the greater stratification of the variable age in the present study. Previous studies report that in individuals under 
PMT and with good oral hygiene the progression of periodontitis increased with age, particularly 50-60 years. However, the loss of periodontal support has been reported to vary from 0.02 to $0.1 \mathrm{~mm} /$ year. Therefore, it may be considered to be mild to moderate. ${ }^{7,22,23}$

It has been reported that individuals with greater severity and extent of periodontitis presented higher dental mortality rates. ${ }^{15}$ The multivariate final model reported that subjects with $10 \%$ of sites with PD between 4 and $6 \mathrm{~mm}$ exhibit 5 times more chances for the occurrence of TL. Previous studies have also established this association. ${ }^{4,7,15}$ This fact highlights the need of long-term evaluation of these subjects. This finding reflects the impact that the progression of periodontitis can produce in dental function and points to the need for a special attention to individuals with a greater severity of periodontitis during programs of PMT, as a way of minimizing future TL.

\section{References}

1. Axelsson P, Nystrom B, Lindhe J. The long-term effect of a plaque control program on tooth mortality, caries and periodontal disease in adults: results after 30 years of maintenance. J Clin Periodontol. 2004 Sep;31(9):749-57.

2. Lorentz TCM, Cota LOM, Cortelli J, Vargas AMD, Costa FO. Prospective study of complier individuals under periodontal maintenance therapy: analysis of clinical periodontal parameters, risk predictors and the progression of periodontitis. $\mathrm{J}$ Clin Periodontol. 2009 Jan;36(1):58-67.

3. Goldman MJ, Ross IF, Goteiner D. Effect of periodontal therapy on patients maintained for 15 years or longer: a retrospective study. J Periodontol. 1986 Jun;57(6):347-53.

4. Hirschfeld L, Wasserman B. A long-term survey of tooth loss in 600 treated periodontal patients. J Periodontol. 1978 May;49(5):225-37.

5. Dannewitz B, Krieger JK, Husing J, Eickholz P. Loss of molars in periodontally treated patients: a retrospective analysis five years or more after active periodontal treatment. J Clin Periodontol. 2006 Jan;33(1):53-61.

6. Wood WR, Greco GW, Mcfall Jr WT. Tooth loss in patients with moderate periodontitis after treatment and long-term maintenance care. J Periodontol. 1989 Sep;60(9):516-20.

7. Chambrone LA, Chambrone L. Tooth loss in well-maintained patients with chronic periodontitis during long-term supportive therapy in Brazil. J Clin Periodontol. 2006 Oct;33(10):75964.

\section{Conclusions}

In this study, the incidence of TL was small and limited to a small number of individuals. Additionally, gender and severity of periodontitis were significantly associated with TL during the monitoring period. Moreover, the identification and the control of predictors of risk associated with dental mortality should be monitored during PMT to minimize TL due to the progression of periodontal disease. Therefore, the stability of periodontal tissues, the control of variables of risk, and the reduction of TL can be attainable goals by programs of PMT, reflecting the efficiency of PMT and providing better quality of life for susceptible individuals.

\section{Acknowledgements}

This study was supported by grants from the Research Foundation of Minas Gerais (Project 10137) and National Counsel of Technological and Scientific Development (Project 471616).

8. Fardal O, Johannessen AC, Linden GJ. Tooth loss during maintenance following periodontal treatment in a periodontal practice in Norway. J Clin Periodontol. 2004 Jul;31(7):5505.

9. Leung WK, Ng DK, Jin L, Corbert EF. Tooth loss in treated periodontitis patients responsible for their supportive care arrangements. J Clin Periodontol. 2006 Apr;33(4):265-75.

10. Miyamoto T, Kumagai T, Jones JA, Van Dyke TE, Nunn ME. Compliance as a prognostic indicator: retrospective study of 505 patients treated and maintened for 15 years. J Periodontol. 2006 Feb;77(2):223-32.

11. Rosling B, Serino G, Hellström MK, Socransky SS, Lindhe J. Longitudinal periodontal tissue alterations during supportive therapy. Findings from subjects with normal and high susceptibility to periodontal disease. J Clin Periodontol. 2001 Mar;28(3):241-9.

12. Carnevale G, Cairo F, Tonetti MS. Long-term effects of supportive therapy in periodontal patients treated with fibre retention osseous resective surgery. II: tooth extractions during active and supportive therapy. J Clin Periodontol. 2007 Apr;34(4):342-8.

13. Faggion CM Jr, Petersilka G, Lang DE, Gerss J, Flemmig TF. Prognostic model for tooth survival in patients treated for periodontitis. J Clin Periodontol. 2007 Mar;34(3):226-31.

14. McFall WT Jr. Tooth loss in 100 treated patients with periodontal disease. J Periodontol. 1982 Sep; 53(9):539-49. 
15. American Academy of Periodontology (AAP). Position Paper. Epidemiology of periodontal diseases. J Periodontol. 2005 Aug;76(8):1406-19.

16. Tonetti MS, Steffen P, Muller-Campanile V, Suvan J, Lang NP. Initial extractions and tooth loss during supportive care in a periodontal population seeking comprehensive care. J Clin Periodontol. 2000 Nov;27(11):824-31.

17. König J, Plagmann H-C, Rühling A, Kocher T. Tooth loss and pocket probings depths in compliant periodontally treated patients - a retrospective analysis. J Clin Periodontol. 2002 Dec;29(12):1092-100.

18. McLeod DE, Lainson PA, Spivey JD. The predictability of periodontal treatment as measured by tooth loss: a retrospective study. Quintessence Int. 1998 Oct;29(10):631-5.

19. Preshaw PM, Heasman PA. Periodontal maintenance in a specialist periodontal clinic and in general dental practice. $\mathrm{J}$ Clin Periodontol. 2005 Mar;32(3):280-6.
20. Bergström J, Eliasson S, Dock J. A 10-year prospective study of tobacco smoking and periodontal health. J Periodontol. 2000 Aug;71(8):1338-47.

21. Jansson L, Lavstedt S, Zimmerman M. Prediction of marginal bone loss and tooth loss - a prospective study over 20 years. J Clin Periodontol. 2002 Aug;29(8):672-8.

22. Costa FO, Cota LOM, Costa JE, Pordeus IA. Periodontal disease progression among young subjects with no preventive dental care: a 52-month follow-up study. J Periodontol. 2007 Feb;78(2):198-203.

23. Heitz-Mayfield LJ, Schätzle M, Löe H, Bürgin W, Anerud A, Boysen $\mathrm{H}$ et al. Incidence, characteristics and time of occurrence of the initial periodontal lesion. J Clin Periodontol. 2003 Oct;30(10): 902-8. 